\title{
NIST Customer Demographics: Collaborative Research and Development Agreements
}

\author{
Nicole Gingrich \\ Isaac Patterson \\ Technology Partnerships Office \\ Innovation and Industry Services
}

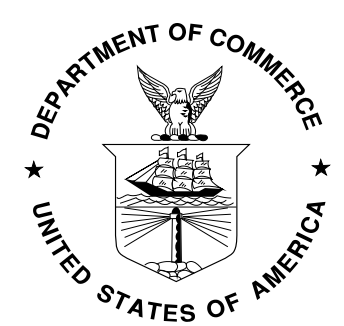

U.S. Department of Commerce Wilbur L. Ross, Jr., Secretary

NLT

National Institute of Standards and Technology U.S. Department of Commerce

National Institute of Standards and Technology Walter Copan, NIST Director and Undersecretary of Commerce for Standards and Technology 


\section{Abstract}

This economic analysis brief summarizes the efforts and results of the data collection and analysis of NIST's CRADA partner information. Summary statistics for CRADA partners are provided for fiscal years 2006 through 2015. Included in the analysis are demographically descriptive variables such as the age, location, industry NAICS codes, number of employees and geographic distribution of NIST CRADA partners. Overall, these features provide an understanding of the demographic characteristics of companies that collaborate on NIST technologies.

\section{Key Findings}

- NIST partners are geographically well dispersed across the United States and tend to be in urban/suburban areas.

- $\quad$ NIST CRADAs tend to be with well-established companies.

- The clear majority of NIST partners are classified as small businesses.

\section{Key Words}

CRADA; customer demographics; technology transfer. 


\section{INTRODUCTION}

Cooperative Research and Development Agreements (CRADAs) are tools that facilitate research partnerships between the National Institute of Standards and Technology (NIST) and U.S. industry, academia, and other organizations. CRADAs offer flexible arrangements for NIST scientific collaborations and research results (NIST, 2016). Therefore, they are important pieces of how NIST transfers technology to its external partners. CRADAs were authorized under the Federal Technology Transfer Act of 1986, 15 USC 3701(12)(a)(1).

Evaluating the demographics of the external partners that work with NIST scientists allows NIST to understand the diverse types of businesses, academic institutions, and other organizations that collaborate with NIST under research and development agreements. Even though NIST has many CRADAs that support specific calibration and accreditation programs, this study focuses on Traditional CRADAs that are not driven by specific, programmatic functions.

The successful use of CRADAs at NIST demonstrates the importance of these agreements and their contributions to the fulfillment of NIST's mission. Despite their importance, little is known about the demography of the U.S. businesses, academic institutions, and other organizations that seek to collaborate with NIST. This publication offers a formal, first look into the geographic and demographic nature of the partners involved in NIST CRADAs.

\section{HYPOTHESES}

For NIST to better understand its partners, analysis is needed to answer questions about the composition and location of these businesses, academic institutions, and other organizations: Where are NIST's partners geographically located in the U.S.? Furthermore, can we classify the locations of these partners into categories that help us understand the likelihood of engagement in collaborative research? What are the ages of the partners that collaborate on research agreements with NIST? Lastly, are NIST's CRADA partners primarily small or large based on numbers of employees?

To answer these questions through testing, the hypotheses and reasons behind them are offered below:

1. The majority of NIST's CRADA partners are expected to be in Maryland or Colorado because these states are the two primary locations of NIST laboratories. Proximity between NIST and its partners reduces travel costs of collaborating with NIST scientists.

2. In addition to geographic location, the majority of NIST's CRADA partners are expected to be in urban areas due to the knowledge that these are often the areas where high-tech and innovative firms are located (Maggioni, 2002).

3. The majority of NIST's CRADA partners are expected to have established themselves many years before entering into a research agreement. This is based

This publication is available free of charge from: https://doi.org/10.6028/NIST.EAB.9 
on the belief that older establishments have more opportunities, both in time and money, to invest in research and development.

4. The majority of NIST's CRADA partners are expected to be small businesses. This hypothesis is based on the trends initialized by the passing of the Technology Transfer Commercialization Act of 2000, 15 USC 3701(4)(c) that gives additional consideration to small businesses when CRADAs are established. Small businesses are those with 500 employees or fewer, as defined by the Small Business Administration (Small Business Administration, n.d.).

Testing these hypotheses will aid NIST in understanding the characteristics of the CRADA partners with which it collaborates.

\section{METHODOLOGY}

Traditional CRADAs were collected from NIST's internal database for this study. Information for each agreement included: agreement number, party name, start date, title of project, and the party's point of contact information, including address and phone number.

With the assistance of Dun and Bradstreet (D\&B), a single DUNS number was selected for each CRADA. A DUNS number is a unique identifier that is used in creating a credit file and maintaining a record of information for many businesses and organizations (Dun \& Bradstreet, n.d.). The DUNS number selection process included reviewing each agreement individually, contacting organizations directly to update their D\&B profiles, and assigning the most appropriate DUNS number for each research partner. ${ }^{1}$

The D\&B search returned a dataset that included information about the industry classification, geographic location, urban and rural classification, the year in which the partner was founded and the number of employees for each CRADA partner. From the CRADAs originally extracted from the NIST database, the sample size was refined to 276 agreements for which D\&B returned available data. Each of these agreements was executed between fiscal years 2006 and $2015 .^{2}$

\footnotetext{
1 The quantity and quality of the data retrieved from D\&B were based upon D\&B's respondents. Unfortunately, some DUNS numbers did not provide any information and others were incomplete. For DUNS numbers that were labeled as "out of business", every effort was made to find the appropriate match.

2 Agreements were removed from the dataset if they were: placeholders in TPO’s database, with individuals, had an international address, or were enacted before FY 2006 or after FY 2015. Individuals were excluded from the dataset because they do not have DUNs numbers associated with them. Foreign companies were excluded due to the unavailability of foreign DUNS numbers.
} 


\section{DAta AND RESUlts}

\subsection{Partner Classification: The North AMERican Industry ClASSIFICATION SYSTEM (NAICS)}

The Federal standard for classifying businesses is the North American Industry Classification System (NAICS). For each partner, the primary NAICS code was identified. Out of the 276 partners, there were 88 unique NAICS codes. The most frequent NAICS code, accounting for $8 \%$ of partners' primary NAICS codes, was "Custom Computer Programming Services”. The second most frequent code was "Software Publishers" at 5\% of the NAICS codes. The third most frequent code was “Computer Systems Design Services” at 4\%.

A packed bubble chart of CRADA Partner NAICS codes can be found in Figure 1 below. The bubbles with frequencies greater or equal to 10 are identified. From the chart, we can begin to see that, while NIST partners with many industries, there are several industries where NIST's research partnerships are somewhat more focused.

Figure 1 - Packed Bubble Chart of CRADA Partner NAICS Codes

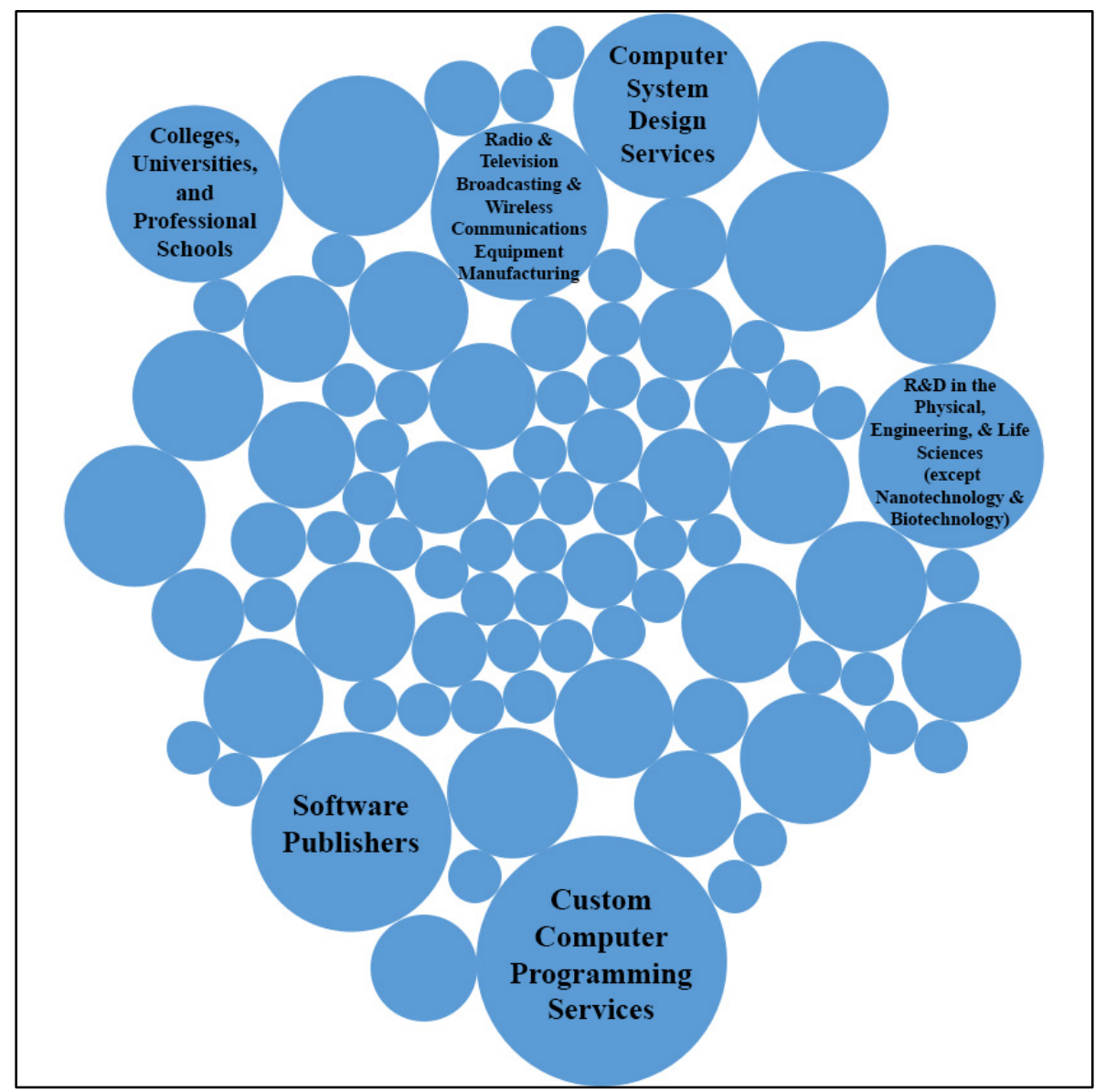




\subsection{Partner Location: Geographic Location ANd Classification}

The sample represents 276 partners located in 34 states and the District of Columbia, as shown in Figure 2 below. California had the largest number of partners involved in CRADAs (53). Virginia was second (30) and Maryland was third (24) in terms of the number of CRADA partners from each state. These three states accounted for $39 \%$ of CRADA partner geographic locations.

One hundred thirty-nine partners self-identified their geographic location. Seventy-one percent of these partners were in urban or suburban environments (49 each). One partner resided in a rural environment. Five partners were in a residential environment. Twentyfive partners were in industrial environments, and the remaining 10 identified themselves in undefined or "other" locations.

The expectations about the geographic locations of NIST's CRADA partners are only partially confirmed by these results. While Maryland hosted the third most partners out of all states, Colorado scored comparatively low (11 partners). This suggests that the proximity to NIST laboratories may not be a deciding factor when determining whether to enter into a partnership with NIST. The geographic classification of NIST's partners is consistent with our expectations that most partners are high-tech firms that experience clustering dynamics.

Figure 2 - Geographic Location of CRADA Partners

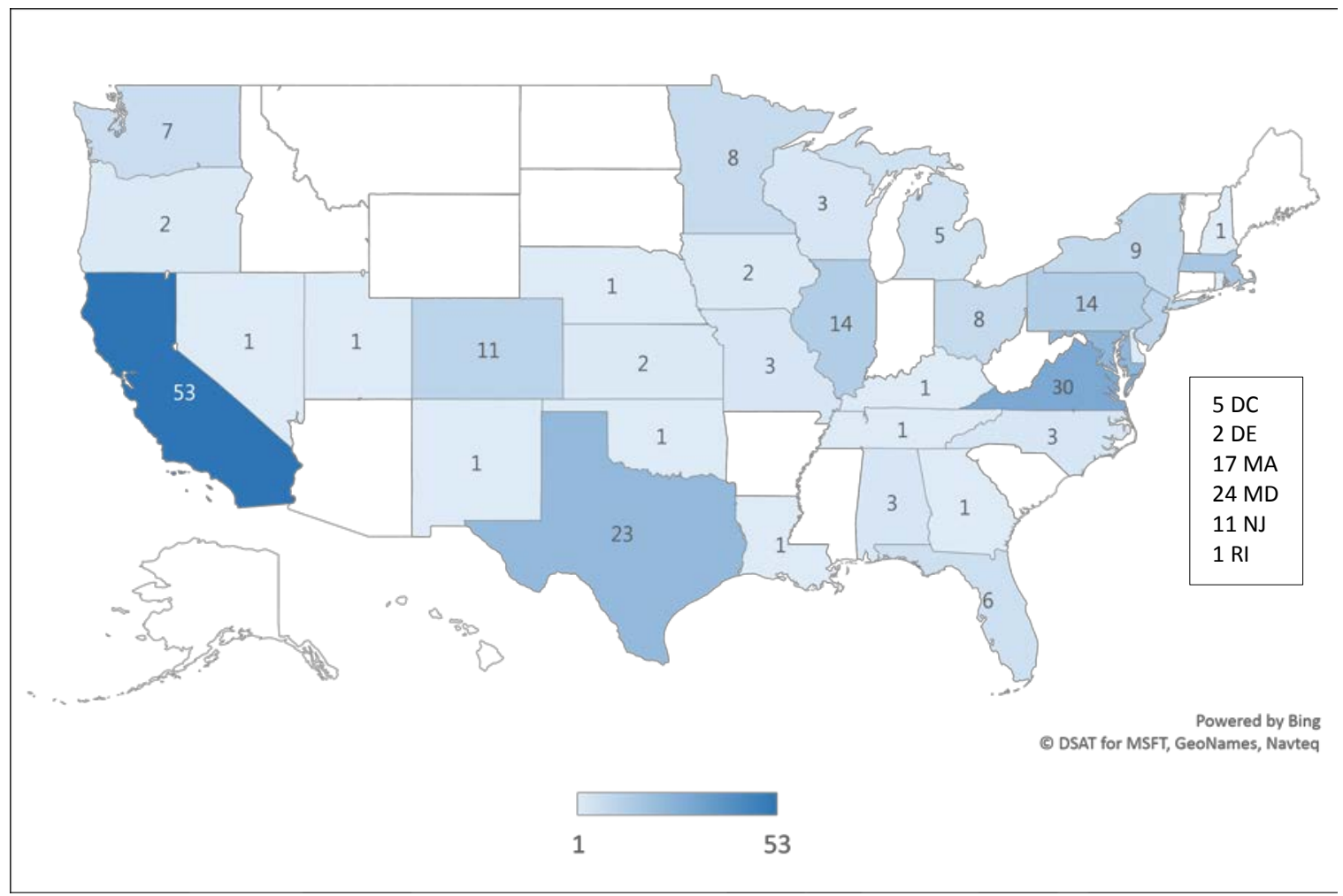

This publication is available free of charge from: https://doi.org/10.6028/NIST.EAB.9 


\subsection{Partner Age: Age at Start of CRAdA}

The age was reported for 225 partners, where data contained both the date the partner was established and the date on which the CRADA was signed. Within this subset of data (represented in Figure 3 below), 13\% of CRADA partners were 5 years old or less. As defined by the U.S. Department of Commerce Annual Report on Technology Transfer, these partners are considered start-ups or young companies (U.S. Department of Commerce, 2015). Partners of ages 6 to 10 years comprise 14\% of the subset of data, while those 11 to 20 years of age represent 28\%. Partners that are 21 years or older make up $45 \%$ of those represented in the data. This subset of the data has a positive skewness of 1.26 and a kurtosis of 0.24 ; therefore, it is not normally distributed. The mean of the data subset is 33.17 years old, the median age is 18 , and the standard deviation is 34.16 . $^{3}$ The results for the distribution of ages of these partners are consistent with our expectation that most CRADAs would be among well-established research partners due to the increased ability to invest in research and development activity over time.

Figure 3- Histogram of Partner Age at Time of CRADA

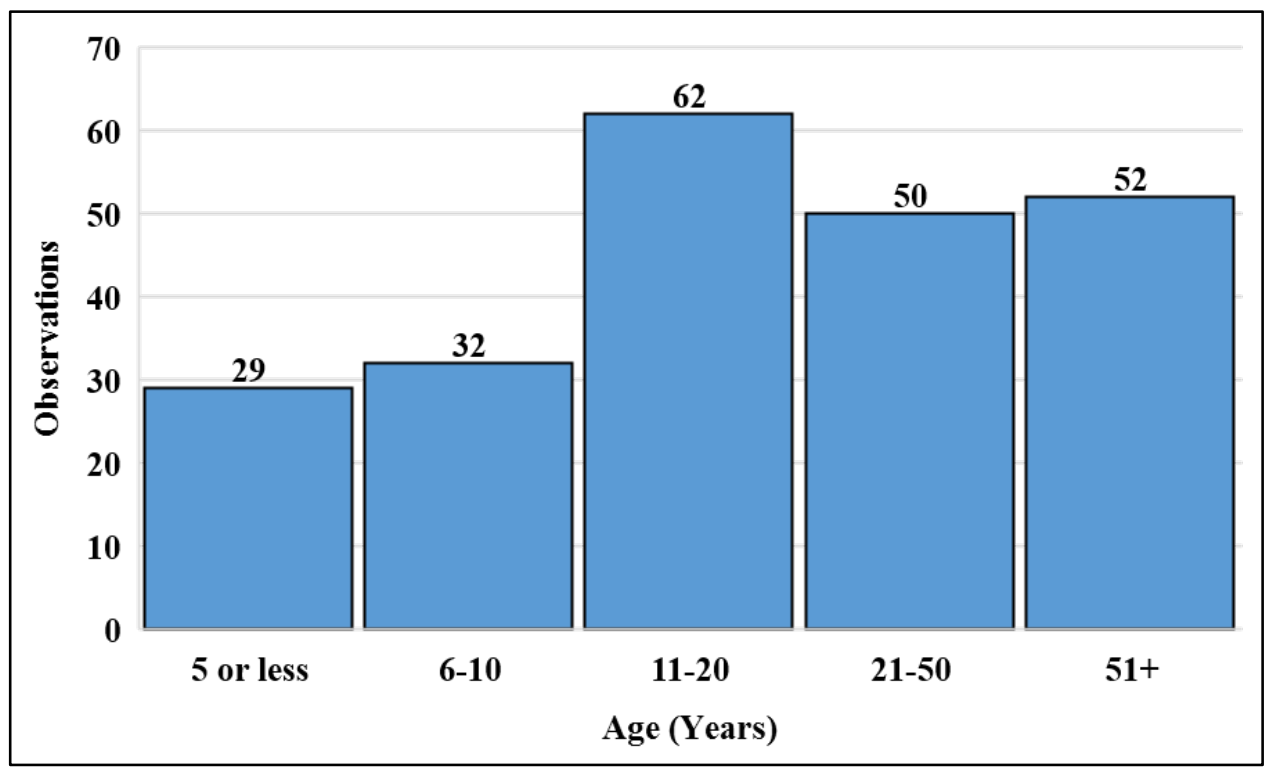

\subsection{PARTNer Size: Number OF Employees}

Two hundred forty-one partners identified the number of employees located at the specific location associated with the DUNS number. ${ }^{4}$ Eighty-six percent of the research partners had fewer than 500 employees at the specific site. Using the definition provided by the Small Business Administration, these CRADA partners are considered small (Small Business Administration, n.d.). These findings are consistent with the hypothesis that the majority of CRADA partners would have fewer than 500 employees on-site.

\footnotetext{
${ }^{3}$ Evidence of a representative sample of NIST CRADAs could not be obtained due to the non-normal distribution of the subset of data on partner age and a lack of information about the ages of the larger dataset.

${ }^{4}$ If a company has multiple locations, only the number of employees at the specific location associated with the DUNS number was reported.
} 
Figure 4 - Bar Chart of CRADA Partner Employment Level

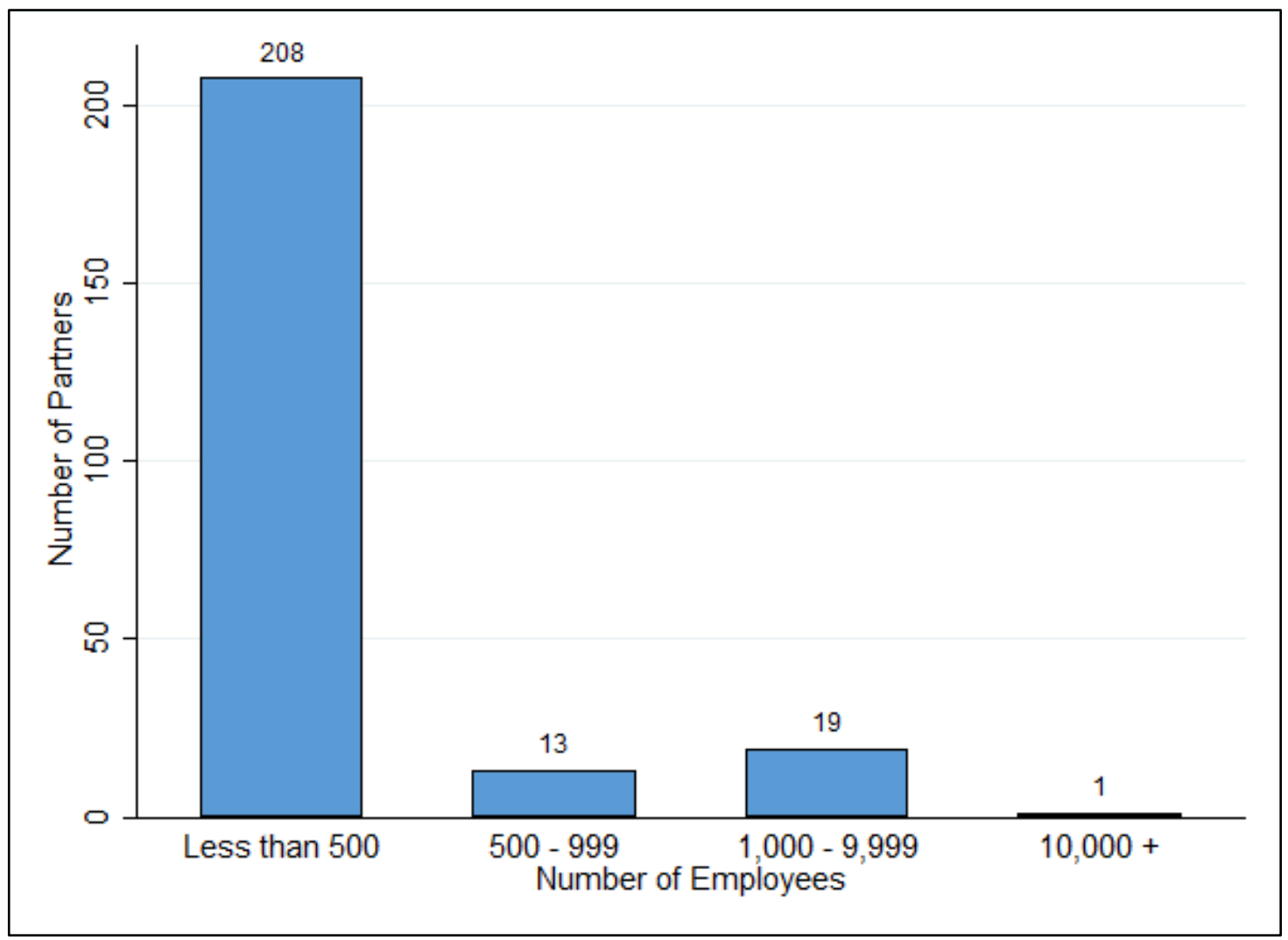

\section{CONCLUSION}

To gain an understanding of NIST partners, this study highlighted several important characteristics of NIST CRADA partners. There are several industries that NIST partnerships permeate more deeply than others such as "Custom Computer Programming Services”, "Software Publishers”, and “Computer Systems Design Services”. The analyses of geographic locations reveal that NIST's partners are geographically welldispersed across the U.S., with the highest concentration of partners in California, Virginia, and Maryland. Furthermore, almost three-fourths of NIST partners operate in urban or suburban areas. NIST's CRADAs are typically collaborations with wellestablished partners. The majority of these CRADA partners are also considered small based on their numbers of employees.

Future analyses can utilize these characteristics to produce case studies regarding the impact of CRADAs on NIST partners over time. Each case study would focus on a specific company and look at different variable types (sales, demographics, employees, finances, social media, et cetera) to examine NIST partner performance before and after CRADA execution. These variables may come from the D\&B-provided data, as well as additional surveying on partner data. 


\section{REFERENCES}

Dun \& Bradstreet. (n.d.). What is a D-U-N-S Number? Retrieved from Dun \& Bradstreet D-U-N-S Number: http://www.dnb.com/duns-number.html

Federal Technology Transfer Act of 1986, Pub. L. No. 99-502, 100 Stat. 1785 (1986).

Maggioni, M. A. (2002). Clustering Dynamics and the Location of High-Tech-Firms. New York: Physica-Verlag Heidelberg.

NIST. (2016, October 6). CRADA. Retrieved from Technology Partnerships Office: https://www.nist.gov/tpo/crada

Small Business Administration. (n.d.). Guide to Size Standards. Retrieved January 8, 2018, from Contracting: https://www.sba.gov/contracting/getting-startedcontractor/make-sure-you-meet-sba-size-standards/guide-size-standards

Technology Transfer and Commercialization Act of 2000, Pub. L. No. 106-404, 114 Stat. 1743 (2000).

U.S. Department of Commerce. (2015). Annual Report on Technology Transfer: Approach and Plans, Fiscal Year 2014 Activities and Achievements. Retrieved from https:/www.nist.gov/sites/default/files/documents/2017/04/28/DOCFY2014-Annual-Tech-Transfer-DOC.pdf 